\title{
Nitrogen dioxide pollution increases vulnerability to COVID-19 through altered immune function
}

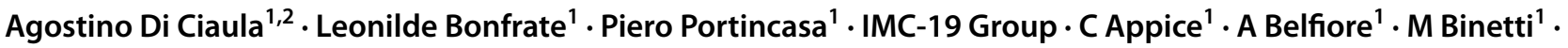

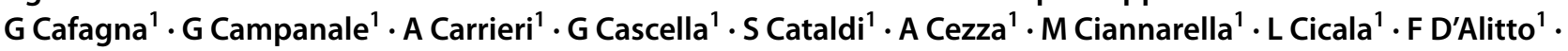 \\ A Dell'Acqua $^{1} \cdot$ L Dell'Anna $^{1} \cdot$ M Diaferia ${ }^{1} \cdot$ G Erroi $^{1} \cdot$ F Fiermonte $^{1} \cdot$ I Galerati $^{1} \cdot$ M Giove $^{1} \cdot$ L Grimaldi $^{1}$. C Mallardi ${ }^{1}$. \\ E Mastrandrea ${ }^{1}$. G. D. Mazelli ${ }^{1}$. G Mersini ${ }^{1}$. G Messina ${ }^{1}$ - M Messina ${ }^{1}$ - A Montesano ${ }^{1}$ - A Noto ${ }^{1}$ - M. E. Novielli ${ }^{1}$. \\ M Noviello ${ }^{1} \cdot$ M. V. Palma ${ }^{1} \cdot$ V. O. Palmieri ${ }^{1} \cdot$ F Passerini $^{1} \cdot$ F Perez $^{1} \cdot C$ Piro $^{1} \cdot$ F Prigigallo $^{1} \cdot$ S Pugliese $^{1} \cdot$ O Rossi $^{1}$. \\ C Stasi $^{1} \cdot \mathrm{R}$ Stranieri ${ }^{1} \cdot \mathrm{G}$ Vitariello ${ }^{1}$
}

Received: 19 October 2021 / Accepted: 29 January 2022 / Published online: 8 February 2022

(c) The Author(s), under exclusive licence to Springer-Verlag GmbH Germany, part of Springer Nature 2022

\begin{abstract}
Previous ecological studies suggest the existence of possible interplays between the exposure to air pollutants and SARSCoV-2 infection. Confirmations at individual level, however, are lacking. To explore the relationships between previous exposure to particulate matter $<10 \mu \mathrm{m}\left(\mathrm{PM}_{10}\right)$ and nitrogen dioxide $\left(\mathrm{NO}_{2}\right)$, the clinical outcome following hospital admittance, and lymphocyte subsets in COVID-19 patients with pneumonia. In 147 geocoded patients, we assessed the individual exposure to $\mathrm{PM}_{10}$ and $\mathrm{NO}_{2}$ in the 2 weeks before hospital admittance. We divided subjects according to the clinical outcome (i.e., discharge at home vs in-hospital death), and explored the lymphocyte-related immune function as an index possibly affecting individual vulnerability to the infection. As compared with discharged subjects, patients who underwent in-hospital death presented neutrophilia, lymphopenia, lower number of T CD45, CD3, CD4, CD16/56+CD3 +, and B CD19+cells, and higher previous exposure to $\mathrm{NO}_{2}$, but not $\mathrm{PM}_{10}$. Age and previous $\mathrm{NO}_{2}$ exposure were independent predictors for mortality. $\mathrm{NO}_{2}$ concentrations were also negatively related with the number of $\mathrm{CD} 45, \mathrm{CD} 3$, and CD4 cells. Previous $\mathrm{NO}_{2}$ exposure is a co-factor independently affecting the mortality risk in infected individuals, through negative immune effects. Lymphopenia and altered lymphocyte subsets might precede viral infection due to nonmodifiable (i.e., age) and external (i.e., air pollution) factors. Thus, decreasing the burden of air pollutants should be a valuable primary prevention measure to reduce individual susceptibility to SARS-CoV-2 infection and mortality.
\end{abstract}

Keywords SARS-CoV-2 $\cdot$ COVID-19 $\cdot$ Lymphocytes $\cdot$ Lymphocyte subsets $\cdot$ Air pollution $\cdot \mathrm{PM}_{10} \cdot \mathrm{NO}_{2} \cdot$ Elderly $\cdot$ Mortality

Responsible Editor: Lotfi Aleya

Agostino Di Ciaula and Leonilde Bonfrate are equal contributors.

Agostino Di Ciaula

agodiciaula@gmail.com

1 Department of Biomedical Sciences and Human Oncology, Clinica Medica "A. Murri”, University of Bari "Aldo Moro" Medical School, Bari, Italy

2 International Society of Doctors for Environment (ISDE), Arezzo, Italy

\section{Introduction}

A novel coronavirus emerged at the end of 2019, known as severe acute respiratory syndrome coronavirus 2 (SARSCoV-2), causing a cluster of pneumonia cases in Wuhan, a city in the Hubei Province of China, and resulting in a global pandemic. Since February 2020, the disease was named COVID-19 by World Health Organization.

COVID-19 has caused, to date and globally, over 271 million confirmed cases and over 5.3 million deaths (World Health Organization 2021).

The disease has high infection rates and variable clinical outcomes, ranging from asymptomatic form to mild clinical presentation, severe respiratory and systemic involvement, and death. Vaccines, available by the end of 2020, can 
successfully prevent SARS-CoV-2 infection; and to date, over 8.3 billion vaccine doses have been administered worldwide (World Health Organization 2021). However, strategies aimed to prevent the worst outcomes following a SARS-CoV-2 infection are still under evaluation. In this respect, several risk factors for severe COVID-19 outcome have been identified (Gao et al. 2021) and include increasing age, comorbidities (i.e., cardiovascular disease, diabetes mellitus, chronic obstructive pulmonary disease, cancer, chronic kidney disease, solid organ or hematopoietic stem cell transplantation, obesity, and smoking), socioeconomic background and gender, several laboratory abnormalities, viral, and genetic factors. Besides these factors, a critical role seems to be played by environmental exposure to air pollutants. In particular, as for other infectious diseases (Ibironke et al. 2019; Rivas-Santiago et al. 2015; Williams et al. 2011), the possibility exists that chronic exposure to air pollution can also affect the immune response to SARSCoV-2 infection, with worse clinical course of disease. Ecological studies suggest that short- and long-term air pollution can negatively affect the clinical outcome in COVID-19 patients (Bowe et al. 2021; Ho et al. 2021; Woodby et al. 2021). These studies, however, rely on aggregated data, while a comprehensive confirmation at individual level and considering pathophysiological implications is still lacking (Villeneuve and Goldberg 2020). In fact, although some individual-level studies are available (Bowe et al. 2021; Elliott et al. 2021; Kogevinas et al. 2021; Lopez-Feldman et al. 2021), evidence are limited by residual biases as an incomplete evaluation of individual confounders, a limited age range of participants, lack of information about exposure to gaseous pollutants or on the immunological status, uncertainty about recent residence of enrolled patients, and lack of data about recent individual exposure.

Furthermore, scarce information is available about the interactions between air pollution and possible immune alterations in patients with COVID-19. In this respect, precise pathways accounting for both disease incidence and clinical course of infected individuals still remain poorly understood, and a clear prognostic value of possible interplays between air pollution, individual immune response, and definitive clinical outcome is lacking.

Among laboratory abnormalities, a decrease in absolute lymphocyte count (lymphopenia of less than $800 / \mu \mathrm{L}$ ) has been frequently described in COVID-19 patients, and this index is considered a predictor of disease severity (Henry et al. 2020; Jin et al. 2020). However, a direct effect of SARS-CoV-2 on B or T lymphocytes seems unlikely, since these cells do not express the angiotensin-converting enzyme 2 (ACE2) receptor (Hamming et al. 2004; Li et al. 2003), the functional receptor for this novel coronavirus in humans (Letko et al. 2020).
Although some secondary mechanisms have been hypothesized (De Biasi et al. 2020; Diao et al. 2020; Song et al. 2020; Xu et al. 2020), the pathways linking SARS-CoV-2 infection and the decreased number of lymphocytes in the peripheral blood are still undetermined. From this point of view, the possibility exists that lymphopenia and decreased lymphocyte subsets can precede, rather than follow, SARSCoV-2 infection, thus conditioning individual vulnerability to COVID-19. Thus, the main aim of the present study is to evaluate, for the first time at individual level, how a previous, medium-term exposure can affect the main features of lymphocyte subsets measured at hospital admission, and the final clinical outcome. These findings have great interest in the determination of individual vulnerability following a SARS-CoV-2 infection, and in terms of possible primary prevention measures oriented at reducing the severity of this disease at a community level.

\section{Subjects and methods}

\section{Subjects}

We studied 147 patients (mean age $66.8 \pm 1.3$ years, age range 31-99 years, 93 males) originating from 10 cities in Apulia (Southern Italy) including Bari and its Province (Bitonto, Altamura, Casamassima, Modugno, Palo del Colle, Barletta, Andria, Molfetta, Monopoli). Patients were admitted to the COVID-unit of internal medicine "A. Murri" of the large Regional Hospital Policlinico of Bari, from March 2020 to April 2021 due to acute SARS-CoV2 infection with pneumonia. Patients were laboratory confirmed to be SARSCoV-2 infected by real-time RT-PCR (nasopharyngeal swab). Data for each individual was collected by medical personnel. All patients underwent a full clinical assessment and blood sampling with a count of white blood cells the same day of hospital admission. Inclusion criteria were (a) diagnosis of acute pneumonia, defined as pulmonary infiltration (CT confirmation); (b) no need for admission to intensive care unit; (c) availability of a valid pre-hospitalization address, and (d) living in the 2 weeks before hospitalization in an urban area where air monitoring stations were present and active.

None of patients received immunomodulating drugs before hospital admission. Patients with known blood diseases were excluded.

\section{Assessment of air pollutants}

The collected information included individuals' address of residence immediately before hospital admission, thus allowing us to geocode enrolled patients and to calculate previous exposure. 
In particular, the average daily air concentrations of particulate matter $<10 \mu \mathrm{m}\left(\mathrm{PM}_{10}\right)$ and nitrogen dioxide $\left(\mathrm{NO}_{2}\right)$ were assessed, for each subject, during the 2 weeks preceding the day of hospital entry and in the specific living area. The exposure to pollutants was determined for each patient considering a specific time-window based on the day of hospital admittance.

The concentration of air pollutants was measured by the network of air monitoring stations positioned in the explored area, and regularly managed by the Regional Environmental Agency (ARPA Puglia https://www.arpa.puglia.it/). Periodic quality control and validation of recorded data are performed by ARPA Puglia according to technical criteria depicted by national and international directives (D. Lgs. 155/2010, EU Directive 2008/50/CE). The concentrations of $\mathrm{PM}_{10}$ and $\mathrm{NO}_{2}$ are available, for each monitoring station, as average daily values expressed in $\mu \mathrm{g} / \mathrm{m}^{3}$. The full database of recorded data is publicly available (http://old.arpa.puglia.it/web/guest/ meta-aria).

\section{Analysis of lymphocyte subsets}

The determination of lymphocyte subsets was available in a random subgroup of 87 patients (mean age $65.1 \pm 1.6$ years, 52 males). All these patients underwent whole blood sampling in the fasting state on the same day of hospital admission. Blood samples were collected by venipuncture into ethylenediamine tetra-acetic acid (EDTA) collection tubes, and lymphocyte subpopulations were subsequently determined in the same day of sampling by a routine procedure (flow cytometer).

\section{Statistical analysis}

We calculated frequencies of categorical variables, means, and standard errors of continuous variables. The chi-squared test (proportions) or the Student's $t$ test for comparison of unpaired data were employed to evaluate differences. The Pearson correlation coefficient was used for correlations. Statistical analyses were performed with NCSS2021 Statistical Software (NCSS, LLC. Kaysville, UT). To calculate odds ratios (OR) and confidence intervals (CI) for air pollutant levels associated with in-hospital mortality, separate logistic regression models were fitted, and results were adjusted for confounders. Models were fitted using R software version 3.1.1 (R Project for Statistical Computing, available from https://www.r-project.org/).

\section{Study approval}

The study protocol was approved by the local Ethics Committee (study No. 6362, authorization No. 0034675).

\section{Results}

There were $112(76.2 \%)$ patients discharged after healing, and $35(23.8 \%)$ in-hospital deaths. Patients who died were older and more often females, than discharged patients. The rate of chronic comorbidities and the average length of hospital stay were similar in the two subgroups (Table 1).

Studying the profile of blood cells count, patients who died showed significantly higher counts of leukocytes, neutrophils, a lower number of lymphocytes as absolute and percentage values, and a higher neutrophils/lymphocytes ratio, than discharged patients (Table 1 ).

Leukocyte $(R=0.18, P=0.03)$ and neutrophil count ( $R=0.22, P=0.02)$ increased, whereas lymphocyte count decreased $(R=-0.20, P=0.01)$ with age.

The subgroup of 87 patients studied for lymphocyte subsets (Table 1) did not differ from the whole group in terms of percent death and discharged. In addition, differences concerning blood cells count between death and discharged group were confirmed. Studying the profile of lymphocyte subsets, patients who died showed lower number of T CD45, CD3, CD4, CD16/56+CD3 + , and B CD19+ cells, than discharged patients. No difference was evident in CD4/CD8 ratio (Table 2).

Negative correlations existed between age and CD45 $(R=-0.35, P=0.008), \mathrm{CD} 3(R=-0.33, P=0.001), \mathrm{CD} 4$ $(R=-0.34, P=0.001), \mathrm{CD} 3+\mathrm{CD} 8+(R=-0.22, P=0.04)$, B CD19 $(R=-0.46, P=0.0001)$ cells.

Table 1 General characteristics and outcome of enrolled COVID-19 patients

\begin{tabular}{llll}
\hline & Death & Discharged & $\mathrm{P}$ \\
\hline$n(\%)$ & $35(23.8)$ & $112(76.2)$ & \\
Age (yrs) & $82.3 \pm 1.9$ & $61.9 \pm 1.2$ & 0.00001 \\
Males/females & $16 / 19$ & $77 / 35$ & 0.03 \\
Females $(\%)$ & 54.3 & 31.3 & 0.01 \\
Comorbidities (presence/absence) & $12 / 23$ & $53 / 59$ & $\mathrm{~ns}$ \\
Hospital stay (days) & $15.6 \pm 1.8$ & $12.6 \pm 0.7$ & $\mathrm{~ns}$ \\
Blood cells count & & & \\
Leukocytes $\left(\times 10^{3}\right.$ cells $\left./ \mu \mathrm{L}\right)$ & $10.3 \pm 1.0$ & $7.29 \pm 0.2$ & 0.006 \\
Neutrophils $\left(\times 10^{3}\right.$ cells $\left./ \mu \mathrm{L}\right)$ & $8.7 \pm 1.0$ & $5.3 \pm 0.2$ & 0.0001 \\
Neutrophils $(\%)$ & $81.4 \pm 1.8$ & $71.3 \pm 1.1$ & 0.00001 \\
Lymphocytes $\left(\times 10^{3}\right.$ cells/ $\left.\mu \mathrm{L}\right)$ & $1.0 \pm 0.1$ & $1.4 \pm 0.08$ & 0.005 \\
Lymphocytes $(\%)$ & $12.7 \pm 1.5$ & $20.2 \pm 0.9$ & 0.00006 \\
Neutrophils/lymphocytes ratio & $12.0 \pm 2.0$ & $5.2 \pm 0.5$ & 0.002 \\
\hline
\end{tabular}

$n s$, not significant; $P M_{10}$, particulate matter $<10 \mu \mathrm{m} ; \mathrm{NO}_{2}$, nitrogen dioxide. Previous exposure to air pollutants is the average, daily air concentration in the 2 weeks preceding the day of hospital admittance. $P$ values obtained by chi-squared test (proportions) or Student's $t$ test for unpaired data 
Table 2 Clinical characteristics and outcome in a subgroup of 87 COVID-19 patients undergoing analysis of lymphocyte subsets

\begin{tabular}{|c|c|c|c|}
\hline & Death & Discharged & $\boldsymbol{P}$ \\
\hline$n(\%)$ & $19(21.8)$ & $68(78.2)$ & \\
\hline Age & $81.9 \pm 1.8$ & $60.4 \pm 1.6$ & 0.00001 \\
\hline Males/females & $9 / 10$ & $43 / 25$ & ns \\
\hline $\begin{array}{l}\text { Comorbidities (presence/ } \\
\text { absence) }\end{array}$ & $11 / 8$ & $46 / 22$ & ns \\
\hline Hospital stay (days) & $14.2 \pm 1.6$ & $11.6 \pm 1.0$ & ns \\
\hline \multicolumn{4}{|l|}{ Blood cells count } \\
\hline Leukocytes $\left(\times 10^{3}\right.$ cells $\left./ \mu \mathrm{L}\right)$ & $9.2 \pm 1.3$ & $7.4 \pm 0.3$ & 0.03 \\
\hline Neutrophils $\left(\times 10^{3}\right.$ cells $\left./ \mu \mathrm{L}\right)$ & $7.9 \pm 1.3$ & $5.5 \pm 0.3$ & 0.03 \\
\hline Neutrophils (\%) & $82.3 \pm 2.4$ & $72.9 \pm 1.5$ & 0.002 \\
\hline $\begin{array}{l}\text { Lymphocytes }\left(\times 10^{3} \text { cells } /\right. \\
\quad \mu \mathrm{L})\end{array}$ & $0.86 \pm 0.1$ & $1.4 \pm 0.1$ & 0.004 \\
\hline Lymphocytes (\%) & $12.0 \pm 2.0$ & $19.1 \pm 1.1$ & 0.004 \\
\hline $\begin{array}{l}\text { Neutrophils/lymphocytes } \\
\text { ratio }\end{array}$ & $13.4 \pm 3.0$ & $5.8 \pm 0.8$ & 0.02 \\
\hline \multicolumn{4}{|l|}{ Lymphocyte subsets } \\
\hline T CD45 (cells/ $\mu \mathrm{L})$ & $750.8 \pm 104.6$ & $1146,3 \pm 76.2$ & 0.004 \\
\hline T CD3 (\%) & $70.7 \pm 3.2$ & $69.1 \pm 1.5$ & ns \\
\hline T CD3 (cells $/ \mu \mathrm{L})$ & $522.8 \pm 73.6$ & $822.1 \pm 65.3$ & 0.02 \\
\hline T CD3 + HLA-DR + (\%) & $3.6 \pm 0.7$ & $3.0 \pm 0.3$ & ns \\
\hline T CD4 (\%) & $42.6 \pm 3.1$ & $44.0 \pm 1.4$ & ns \\
\hline T CD4 (cells $/ \mu \mathrm{L})$ & $303.8 \pm 46.4$ & $540.0 \pm 50.9$ & 0.01 \\
\hline $\mathrm{CD} 3+\mathrm{CD} 8+(\%)$ & $26.2 \pm 3.3$ & $23.2 \pm 1.1$ & ns \\
\hline $\mathrm{CD} 3+\mathrm{CD} 8+($ cells $/ \mu \mathrm{L})$ & $204.0 \pm 41.8$ & $265.2 \pm 20.5$ & ns \\
\hline $\mathrm{CD} 3-\mathrm{CD} 8+(\%)$ & $3.2 \pm 0.6$ & $3.1 \pm 0.3$ & ns \\
\hline CD3-CD8 + (cells/ $\mu \mathrm{L})$ & $26.7 \pm 7.4$ & $31.1 \pm 3.3$ & ns \\
\hline $\mathrm{CD} 16 / 56+\mathrm{CD} 3-(\%)$ & $17.4 \pm 2.7$ & $14.0 \pm 1.2$ & ns \\
\hline $\mathrm{CD} 16 / 56+\mathrm{CD} 3-($ cells $/ \mu \mathrm{L})$ & $155.4 \pm 39.2$ & $138.3 \pm 11.8$ & ns \\
\hline $\mathrm{CD} 16 / 56+\mathrm{CD} 3+(\%)$ & $4.3 \pm 0.8$ & $5.5 \pm 0.6$ & ns \\
\hline $\mathrm{CD} 16 / 56+\mathrm{CD} 3+($ cells $/ \mu \mathrm{L})$ & $31.3 \pm 7.4$ & $62.3 \pm 7.3$ & 0.03 \\
\hline B CD19 (\%) & $11.2 \pm 1.9$ & $16.4 \pm 1.0$ & 0.02 \\
\hline B CD19 (cells/ $\mu \mathrm{L})$ & $67.0 \pm 11.0$ & $181.9 \pm 16.4$ & 0.0004 \\
\hline $\mathrm{CD} 4 / \mathrm{CD} 8$ ratio & $2.5 \pm 0.5$ & $2.3 \pm 0.2$ & ns \\
\hline
\end{tabular}

$n s$, not significant. $P$ values obtained by chi-squared test (proportions) or Student's $t$ test for unpaired data

\section{Assessment of air pollutants}

Enrolled patients were geolocated according to their residential address. As depicted in Fig. 1, the analysis of air pollutants revealed that the exposure to $\mathrm{NO}_{2}$ in the 2 weeks before hospital admittance was significantly higher in patients who died $\left(51.7 \pm 2.1 \mu \mathrm{g} / \mathrm{m}^{3}\right)$, than in patients discharged after healing $\left(46.3 \pm 1.3 \mu \mathrm{g} / \mathrm{m}^{3}, P=0.04\right)$. The average air concentration of $\mathrm{PM}_{10}$ in the 2 weeks before hospital admittance was similar in patients who underwent in-hospital death $\left(25.1 \pm 1.1 \mu \mathrm{g} / \mathrm{m}^{3}\right)$ and in discharged patients $\left(23.8 \pm 0.7 \mu \mathrm{g} / \mathrm{m}^{3}, P=\mathrm{NS}\right)$.

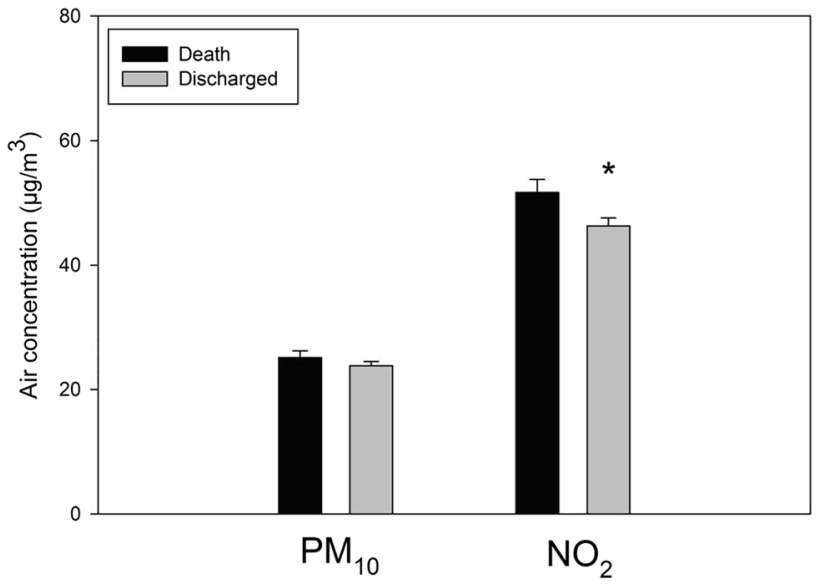

Fig. 1 Average daily air concentrations of $\mathrm{PM}_{10}$ and $\mathrm{NO}_{2}$ during the 2 weeks preceding the day of hospital admittance in COVID-19 patients admitted for pneumonia, who underwent in-hospital death or discharge at home. Patients were geocoded based on the residential address. The exposure to $\mathrm{PM}_{10}$ and $\mathrm{NO}_{2}$ before hospital admittance was assessed, for each subject, in the specific living area. Asterisk indicates $P=0.04$

Logistic regression models indicated age (OR 1.19 [95\% CI 1.11-1.26]) and the average $\mathrm{NO}_{2}$ air concentrations in the 2 weeks before hospital admission (OR 1.029 [95\% CI $1.0008-1.059]$ ) as significant predictors of mortality. The increased mortality risk linked with previous $\mathrm{NO}_{2}$ exposure persisted after adjusting for age, gender, and presence of comorbidities (OR 1.045 [95\% CI 1.003-1.088]). No significant effect was detected for $\mathrm{PM}_{10}$ (Fig. 2).

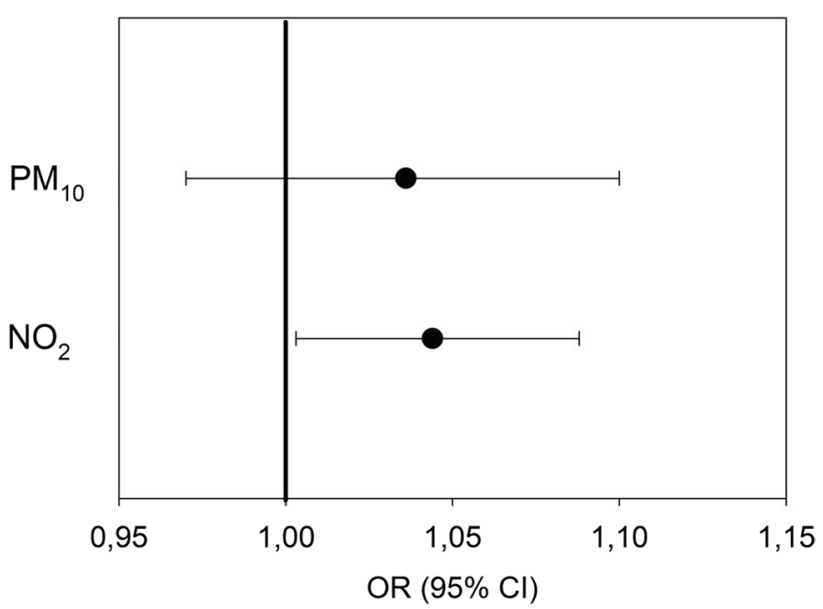

Fig. 2 Odds ratios and 95\% confidence interval (CI) for the association between average air concentrations of $\mathrm{PM}_{10}$ and $\mathrm{NO}_{2}$ in the 2 weeks before hospital admittance and in-hospital COVID-19 death, adjusted for age, sex, and presence of comorbidities, as covariates 
$\mathrm{NO}_{2}$ air concentration decreased with the percentage of lymphocytes $(R-0.20, P=0.01)$, and increased with the percentage of neutrophils $(R=0.18, P=0.02)$.

When lymphocyte subsets were considered, negative correlations were present between $\mathrm{NO}_{2}$ air concentrations and the blood count of T CD45 $(R-0.27, P=0.01), \mathrm{CD} 3$ $(R-0.26, P=0.01)$, and CD4 cells $(R-0.24, P=0.028)$.

\section{Discussion}

We confirm the link between neutrophilia, lymphopenia, and risk of death in patients hospitalized for COVID-19 pneumonia and admitted to internal medicine division. While confirming the negative prognostic value of age, we also show for the first time that $\mathrm{NO}_{2}$ exposure in the 2 weeks before hospital admittance is a co-factor contributing to mortality risk through immune effects. In fact, our data show a link between both age and $\mathrm{NO}_{2}$ exposure with blood count of multiple lymphocyte subset. The findings point to negative immune outcomes likely predisposing to SARS-CoV-2 infection and worse clinical course.

Previous evidence from ecological studies suggested that air pollution can affect both incidence $(\mathrm{H} \mathrm{Li}$ et al. 2020a, b) and clinical course of COVID-19 (Bowe et al. 2021; Ho et al. 2021; Woodby et al. 2021), and that the rapid development of the pandemic in some geographic regions may have depended on air pollution in the same areas (Ho et al. 2021; Stufano et al. 2021).

Short-term exposures to $\mathrm{NO}_{2}, \mathrm{PM}_{2.5}$, and $\mathrm{PM}_{10}$ have been linked with COVID-19 incidence in a Chinese time series study (H Li et al. 2020a, b). Data from 33 European countries also indicate direct correlations between the cumulative number of COVID-19 deaths and air concentrations of $\mathrm{PM}_{10}, \mathrm{PM}_{2.5}$, ammonia, sulfur dioxide, nonmethane volatile organic compounds, $\mathrm{NO}_{2}$, and greenhouse gas elements. The strongest correlations were emerged for $\mathrm{PM}_{2.5}$ and nitrogen oxides (Lembo et al. 2021).

The link between air pollution and the clinical outcome in COVID-19 patients has also been suggested in the case of long-term exposures to critical levels of $\mathrm{PM}_{2.5}$ and nitrogen oxides, which have been linked with COVID-19 morbidity and mortality rates (Barnett-Itzhaki and Levi 2021; Hou et al. 2021).

These reports, however, are limited by their ecological design. In fact, the use of aggregated data (i.e., analyses conducted at a population level) can provide useful suggestions in terms of prevention policies but, since results are not adjusted for individual variables, an accurate evaluation of pathogenic pathways and cause-effect mechanisms is not possible.

A recent individual-level study showed a direct effect between exposure to $\mathrm{PM}_{2.5}$ and nitrogen dioxide, and the severity of disease. However, data from the cited study seem to exclude that long-term exposure to air pollutants can affect host susceptibility to SARS-CoV-2 infection, based on serological data (i.e., antibody response) (Kogevinas et al. 2021).

At variance with previous studies, we enrolled a wellcharacterized cohort of hospitalized subjects, including precise measurement of recent individual exposure at a residential level, the analysis of lymphocyte subsets, and the effect of possible individual confounders. This approach allowed us to avoid many sources of bias limiting previous studies.

In this respect, the present study supports, with individual findings, data from previous ecological studies, underlying the role of $\mathrm{NO}_{2}$ exposure on the clinical outcome of COVID19 pneumonia. We found that age and average $\mathrm{NO}_{2}$ air concentrations in the 2 weeks before hospital admission were significant predictors of mortality in patients hospitalized following an acute SARS-CoV-2 infection and pneumonia. According to results from logistic regression models, however, the $\mathrm{NO}_{2}$-related death risk was independent from age, gender, and presence of comorbidities.

The evidence of a link between $\mathrm{NO}_{2}$ air concentration and the mortality risk confirms a previous, large ecological survey in two Northern Italy regions (Veneto and EmiliaRomagna), showing an association between ground-level nitrogen dioxide concentrations and daily COVID-19 mortality (Filippini et al. 2021). Several other studies reported a link between the exposure to nitrogen oxides and COVID-19 morbidity and mortality at a population level (Barnett-Itzhaki and Levi 2021; Hou et al. 2021; Lembo et al. 2021; H Li et al. 2020a, b), and the evidence that this relationship seems particularly critical during elderly (Dales et al. 2021).

At variance with previous epidemiologic observations suggesting negative health effects of both short- and longterm exposure to particulate matter (Barnett-Itzhaki and Levi 2021; Hou et al. 2021; Lembo et al. 2021; H Li et al. $2020 \mathrm{a}, \mathrm{b}$ ), in our series, $\mathrm{PM}_{10}$ exposure seems to have no significant effect on COVID-19 mortality. This discrepancy might be explained, at least in part, with the evidence that the effect of $\mathrm{PM}_{10}$ on COVID-19 fatality is concentrationdependent, and with the lower average $\mathrm{PM}_{10}$ air concentrations recorded, in our study, in the explored areas (mean $24.1 \pm 0.6 \mu \mathrm{g} / \mathrm{m}^{3}$ ), as compared with $\mathrm{PM}_{10}$ levels measured in previous ecological studies, in particular from China (on average $>50 \mu \mathrm{g} / \mathrm{m}^{3}$ ) (Hou et al. 2021; H Li et al. 2020a, b). On the other hand, data from an individual-level study in Mexico-city indicated that exposure to $\mathrm{PM}_{2.5}$ was positively related with COVID-19 mortality, but that this effect was mainly driven by long-term exposure (Lopez-Feldman et al. 2021). This might be an additional element explaining the lack of significant effects of particulate matter on individual 
mortality observed, in the present study, following shortterm exposure.

Although further surveys better exploring short- and long-term exposure to different concentrations of particulate matter in COVID-19 patients are certainly needed, data from the present study and from previous surveys indicate a diverse role played by exposures to $\mathrm{NO}_{2}$ and particulate matter. This hypothesis is confirmed by a study conducted in a large cohort of English COVID-19 patients. Authors explored the effect of long-term exposure to $\mathrm{NO}_{2}$ and $\mathrm{PM}_{2.5}$ on mortality using a high geographical resolution, and adjusting results for individual (age, sex, ethnicity) and area-based prevalence of confounders. The analysis demonstrated an association between long-term exposure to $\mathrm{NO}_{2}$ and COVID-19 mortality, with effects proportional to $\mathrm{NO}_{2}$ air concentration, but with no convincing effects of $\mathrm{PM}_{2.5}$ exposure (Konstantinoudis et al. 2021). Although the spatial resolution used in the cited study was relatively small as compared with other ecological studies, the study design was still ecological, and results cannot fully reflect individual associations. Results from the cited study, however, are in line with our findings, that revealed a $\mathrm{NO}_{2}$-related mortality risk independent from individual comorbidities. Of note, Konstantinoudis et al. (Konstantinoudis et al. 2021) indicated that considering the area prevalence of major comorbidities (i.e., hypertension, diabetes, chronic obstructive pulmonary diseases) as confounder did not change their results. Their results support our findings and point to the existence of an independent effect of $\mathrm{NO}_{2}$ exposure on SARS-CoV-2 mortality. This conclusion is in line with a number of previous evidence demonstrating clear relationships between $\mathrm{NO}_{2}$ exposure, lung inflammation and functional abnormalities (Jiang et al. 2019; Johannson et al. 2014; Sack et al. 2017), vulnerability to respiratory infections (Kirwa et al. 2021), lymphopenia, and reduced amount of lymphocyte subsets (Frampton et al. 2002; Sandstrom et al. 1992; Solomon et al. 2000; Steenhof et al. 2014). Human studies showed that exposure to $\mathrm{NO}_{2}$ is able to induce acute exacerbation of idiopathic pulmonary fibrosis (Johannson et al. 2014), to increase interstitial lung abnormality (Sack et al. 2017), to promote respiratory inflammation, and to affect lung function acting by epigenetic mechanisms (i.e., hypomethylation of the arginase - nitric oxide synthase pathway) (Jiang et al. 2019).

In a large cohort of adults explored over 12 years (multiethnic study of atherosclerosis, MESA), an increase in residential concentration of $\mathrm{NO}_{2}$ from the 25th to the 75th percentile in the previous $2-6$ weeks period was linked with $21 \%$ higher risk of reporting a recent respiratory infection (Kirwa et al. 2021).

An experimental study in healthy volunteers undergoing controlled $\mathrm{NO}_{2}$ exposure and subsequent bronchoalveolar lavage (BAL) demonstrated, in BAL, an increased percentage of neutrophils and a decrease in T-helper cells following $\mathrm{NO}_{2}$ exposure, as compared with filtered air (Solomon et al. 2000). Healthy volunteers exposed in the short-term $(3 \mathrm{~h})$ to $\mathrm{NO}_{2}$ showed a subsequent decrease in blood count of total and $\mathrm{T}$ lymphocytes, mild airway inflammation, and increased susceptibility to respiratory syncytial virus (Frampton et al. 2002). Furthermore, repeated exposures to $\mathrm{NO}_{2}$ in healthy volunteers induced decreased amount of B and natural killer-cells in BAL and lymphopenia in peripheral blood (Sandstrom et al. 1992). Of note, in a series of healthy volunteers, the significant decrease in the number of lymphocytes recorded following short-term $(5 \mathrm{~h})$ air pollution exposure and the negative correlation between the number of lymphocytes and $\mathrm{NO}_{2}$ air concentrations were independent from other air pollutants, underlying the role played by this specific gaseous pollutant (Steenhof et al. 2014).

Taken together, these findings confirm the negative effects of $\mathrm{NO}_{2}$ exposure on lymphocyte-linked immune function and support results obtained in the present study, suggesting the possibility that altered lymphocyte subsets linked with environmental factors can precede, rather than follow, SARS-CoV-2 infection, increasing individual vulnerability to COVID-19.

Our data confirm the link of neutrophilia and lymphopenia at admission with progression to severe disease and death (Henry et al. 2020; Jin et al. 2020). Neutrophilia can be explained with the extent of inflammation and with the cytokine storm linked with the progression of viral infection (Wang et al. 2020).

Lymphopenia, on the other hand, has been frequently described in COVID-19 patients (G Chen et al. 2020a, b; T Chen et al. 2020a, b; Henry et al. 2020; Jin et al. 2020; Liu et al. 2021; Zhang et al. 2020), although possible causes are still uncertain. Direct negative effects of SARS-CoV-2 on human lymphocytes seem unlikely, since the ACE2 receptor, the functional receptor for this virus in humans (Letko et al. 2020), is not expressed in B and T lymphocytes (Hamming et al. 2004; Li et al. 2003). Since a diffused lymphocyte infiltration in the lung has been reported during severe COVID19 pneumonia (Song et al. 2020; Xu et al. 2020), a decreased blood cell count might be secondary to lymphocyte isolation in the severely inflamed lung, with activation-induced apoptosis (Song et al. 2020). An additional hypothesis might be an exhaustion of $\mathrm{T}$ cells in peripheral blood following a severe clinical presentation, due to reduced replicative abilities upon stimulation (De Biasi et al. 2020; Diao et al. 2020).

Besides a decrease in total lymphocyte count, previous observations also reported decreased lymphocyte subsets following SARS-CoV-2 infection, mainly in terms of decreased T CD45, CD3, CD4, CD8, and B cells (Iannetta et al. 2021; Jin et al. 2020; Kazancioglu et al. 2021; Yan et al. 2021). These subsets play a critical role in immune 
system function and in the clearance of the virus; and a reduced number of these cells has been reported, in particular, in severe and critical COVID-19 patients (Iannetta et al. 2021; Yan et al. 2021).

The evidence of decreased lymphocyte subsets has been confirmed in our series, with lower blood counts of CD45, CD3, CD4, CD16/56 + CD3 +, and B CD19 cells in patients who underwent in-hospital death, as compared with discharged patients.

The decrease count of CD45 seems of particular relevance, since this event can lead to an impaired $\mathrm{T}$ cell activation (Altin and Sloan 1997), with subsequent T- and B-lymphocyte dysfunction and a critical, combined immune deficiency (Rheinlander et al. 2018).

Of note, results from the present study indicated that the medium-term levels of $\mathrm{NO}_{2}$ air concentration before hospital admittance were negatively correlated with the blood count of T CD45, CD3, and CD4 cells, pointing to environmental exposure to this gaseous pollutant as a contributing factor in the onset of lymphocytopenia and, possibly, in determining the clinical outcome of infected patients. From this point of view, our results are in line with previous findings revealing, in patients with severe COVID-19, a decreased blood count of CD3, CD4, and CD45 cells in the first 3 days after hospital admission, with a gradual recovery in the survival group, but persistent low levels in the death group (Q Li et al. 2020a, b).

In the present series, subjects who underwent in-hospital death were older than discharged patients. Our findings confirm elderly as a risk factor for COVID-19 (Wu et al. 2020), and the negative prognostic value of advanced age in these patients (Jin et al. 2020; Wu et al. 2020). Our data also suggest that this effect might be secondary to an altered immune function in aged patients (Fulop et al. 2005; Jin et al. 2020; Valiathan et al. 2016), rather than to the viral infection. In this respect, a most evident decrease in the count of total lymphocyte, CD3, CD8, and CD45 cells has been previously reported in aged patients with COVID-19 as compared with younger groups, as an expression of a progressive deterioration of the immune function with increasing age (Jin et al. 2020).

Of note, however, in the present series, results from logistic regression models indicated that the negative effect of $\mathrm{NO}_{2}$ exposure before hospital admission on the mortality risk was independent from age.

In our study, a significant point of strength is the analysis, at individual level, of the relationships between mediumterm exposure and air pollutants, indices of immune function, and the clinical outcome in patients infected by SARSCoV-2 and developing pneumonia.

The main limitations of the present study are a relatively low number of enrolled cases, the lack of evaluation of indoor individual exposure, and the older age of patients who underwent in-hospital death. However, findings clearly point to the previous exposure to air pollution as an external factor influencing the individual mortality risk following a SARSCoV-2 pneumonia, proportionally to the air concentration of pollutants, independently from age, and through pathways involving the immune function. Another limitation, in the present study, is the outdoor exposure of enrolled subjects to relatively low $\mathrm{PM}_{10}$ air concentrations. This is due to the scarcity, in the living areas of enrolled subjects, of relevant anthropogenic sources of $\mathrm{PM}_{10}$ (mainly industrial plants) and to vehicular traffic and home heating generating nitrogen oxides as prevalent sources of urban pollution. Further researches are needed to expand our findings, evaluating in particular subjects living in geographical areas mainly characterized by industrial pollution, and larger series of subjects with a broader age range, also including pediatric age.

In conclusion, our results point to both $\mathrm{NO}_{2}$ exposure and elderly as relevant co-factors able to increase individual vulnerability to SARS-CoV-2 infection through immunosuppression and increased inflammation, leading to a worse clinical outcome. Besides the role of unmodifiable factors (i.e., age, comorbidities, genetic factors), our data suggest that lowering the level of environmental pollution can increase the possibility of a less severe outcome following a SARS-CoV-2 infection, in particular in fragile individuals as aged people.

In fact, according to available data, lymphopenia and the reduced lymphocyte subsets recorded in patients with COVID-19 and in those with a severe course of disease might precede the viral infection, with a major role for both age and environmental pollution. In this respect, a decrease in the environmental burden of air pollutants should be considered a valuable primary prevention measure to reduce individual susceptibility to SARS-CoV-2 infection and COVID-19-related mortality.

Author contribution ADC wrote the study protocol. ADC, LB, and PP analyzed and interpreted data, wrote, and revised the final version. The IMC-19 Group participated to data collection.

All authors read and approved the final manuscript.

Data availability The datasets used and/or analyzed during the current study are available from the corresponding author on reasonable request.

\section{Declarations}

Ethics approval and consent to participate The study protocol was approved by the local Ethics Committee (study No6362, authorization No. 0034675).

Consent for publication Not applicable.

Competing interests The authors declare no competing interests. 


\section{References}

Altin JG, Sloan EK (1997) The role of cd45 and cd45-associated molecules in t cell activation. Immunol Cell Biol 75:430-445

Barnett-Itzhaki Z, Levi A. 2021. Effects of chronic exposure to ambient air pollutants on covid-19 morbidity and mortality - a lesson from oecd countries. Environ Res 195:110723.

Bowe B, Xie Y, Gibson AK, Cai M, van Donkelaar A, Martin RV, et al. 2021. Ambient fine particulate matter air pollution and the risk of hospitalization among covid-19 positive individuals: cohort study. Environ Int 154:106564.

Chen G, Wu D, Guo W, Cao Y, Huang D, Wang H et al (2020a) Clini$\mathrm{cal}$ and immunological features of severe and moderate coronavirus disease 2019. J Clin Investig 130:2620-2629

Chen T, Wu D, Chen H, Yan W, Yang D, Chen G, et al. 2020b. Clinical characteristics of 113 deceased patients with coronavirus disease 2019: Retrospect Stud BMJ 368:m1091.

Dales R, Blanco-Vidal C, Romero-Meza R, Schoen S, Lukina A, Cakmak S. 2021. The association between air pollution and covid-19 related mortality in Santiago, Chile: a daily time series analysis. Environ Res 198:111284.

De Biasi S, Meschiari M, Gibellini L, Bellinazzi C, Borella R, Fidanza $\mathrm{L}$ et al (2020) Marked t cell activation, senescence, exhaustion and skewing towards th17 in patients with covid-19 pneumonia. Nat Commun 11:3434

Diao B, Wang C, Tan Y, Chen X, Liu Y, Ning L et al (2020) Reduction and functional exhaustion of $\mathrm{t}$ cells in patients with coronavirus disease 2019 (covid-19). Front Immunol 11:827

Elliott J, Bodinier B, Whitaker M, Delpierre C, Vermeulen R, Tzoulaki I et al (2021) Covid-19 mortality in the UK biobank cohort: revisiting and evaluating risk factors. Eur J Epidemiol 36:299-309

Filippini T, Rothman KJ, Cocchio S, Narne E, Mantoan D, Saia M, et al. 2021. Associations between mortality from covid-19 in two Italian regions and outdoor air pollution as assessed through tropospheric nitrogen dioxide. Sci Total Environ 760:143355.

Frampton MW, Boscia J, Roberts NJ Jr, Azadniv M, Torres A, Cox $C$ et al (2002) Nitrogen dioxide exposure: effects on airway and blood cells. Am J Physiol Lung Cell Mol Physiol 282:L155-165

Fulop T, Larbi A, Wikby A, Mocchegiani E, Hirokawa K, Pawelec G (2005) Dysregulation of t-cell function in the elderly: scientific basis and clinical implications. Drugs Aging 22:589-603

Gao YD, Ding M, Dong X, Zhang JJ, Kursat Azkur A, Azkur D et al (2021) Risk factors for severe and critically ill Covid-19 patients: a review. Allergy 76:428-455

Hamming I, Timens W, Bulthuis ML, Lely AT, Navis G, van Goor H (2004) Tissue distribution of ace 2 protein, the functional receptor for sars coronavirus. A first step in understanding sars pathogenesis. J Pathol 203:631-637

Henry B, Cheruiyot I, Vikse J, Mutua V, Kipkorir V, Benoit J, et al. 2020. Lymphopenia and neutrophilia at admission predicts severity and mortality in patients with Covid-19: a meta-analysis. Acta Biomed 91:e2020008.

Ho CC, Hung SC, Ho WC. 2021. Effects of short- and long-term exposure to atmospheric pollution on Covid-19 risk and fatality: analysis of the first epidemic wave in northern Italy. Environ Res 199:111293.

Hou CK, Qin YF, Wang G, Liu QL, Yang XY, Wang H (2021) Impact of a long-term air pollution exposure on the case fatality rate of Covid-19 patients—a multicity study. J Med Virol 93:2938-2946

Iannetta M, Buccisano F, Fraboni D, Malagnino V, Campogiani L, Teti E et al (2021) Baseline t-lymphocyte subset absolute counts can predict both outcome and severity in Sars-Cov-2 infected patients: a single center study. Sci Rep 11:12762

Ibironke O, Carranza C, Sarkar S, Torres M, Choi HT, Nwoko J, et al. 2019. Urban air pollution particulates suppress human t-cell responses to mycobacterium tuberculosis. Int J Environ Res Public Health 16.

Jiang Y, Niu Y, Xia Y, Liu C, Lin Z, Wang W, et al. 2019. Effects of personal nitrogen dioxide exposure on airway inflammation and lung function. Environ Res 177:108620.

Jin M, Shi N, Wang M, Shi C, Lu S, Chang Q et al (2020) Cd45: a critical regulator in immune cells to predict severe and non-severe Covid-19 patients. Aging 12:19867-19879

Johannson KA, Vittinghoff E, Lee K, Balmes JR, Ji W, Kaplan GG et al (2014) Acute exacerbation of idiopathic pulmonary fibrosis associated with air pollution exposure. Eur Respir J 43:1124-1131

Kazancioglu S, Yilmaz FM, Bastug A, Sakalli A, Ozbay BO, Buyuktarakci $C$ et al (2021) Lymphocyte subset alteration and monocyte cd4 expression reduction in patients with severe Covid-19. Viral Immunol 34:342-351

Kirwa K, Eckert CM, Vedal S, Hajat A, Kaufman JD. 2021. Ambient air pollution and risk of respiratory infection among adults: evidence from the multiethnic study of atherosclerosis (mesa). BMJ Open Respir Res 8.

Kogevinas M, Castano-Vinyals G, Karachaliou M, Espinosa A, de Cid $\mathrm{R}$, Garcia-Aymerich J, et al. 2021. Ambient air pollution in relation to Sars-Cov-2 infection, antibody response, and Covid-19 disease: a cohort study in Catalonia, Spain (covicat study). Environ Health Perspect 129:117003.

Konstantinoudis G, Padellini T, Bennett J, Davies B, Ezzati M, Blangiardo M. 2021. Long-term exposure to air-pollution and Covid-19 mortality in England: a hierarchical spatial analysis. Environ Int 146:106316.

Lembo R, Landoni G, Cianfanelli L, Frontera A. 2021. Air pollutants and Sars-Cov-2 in 33 European countries. Acta Biomed 92:e2021166.

Letko M, Marzi A, Munster V (2020) Functional assessment of cell entry and receptor usage for Sars-Cov-2 and other lineage $b$ betacoronaviruses. Nat Microbiol 5:562-569

Li H, Xu XL, Dai DW, Huang ZY, Ma Z, Guan YJ (2020a) Air pollution and temperature are associated with increased Covid-19 incidence: a time series study. Int J Infect Dis 97:278-282

Li Q, Xu W, Li WX, Huang CL, Chen L (2020b) Dynamics of cytokines and lymphocyte subsets associated with the poor prognosis of severe Covid-19. Eur Rev Med Pharmacol Sci 24:12536-12544

Li W, Moore MJ, Vasilieva N, Sui J, Wong SK, Berne MA et al (2003) Angiotensin-converting enzyme 2 is a functional receptor for the sars coronavirus. Nature 426:450-454

Liu G, Jiang X, Zeng X, Pan Y, Xu H (2021) Analysis of lymphocyte subpopulations and cytokines in Covid-19-associated pneumonia and community-acquired pneumonia. J Immunol Res 2021:6657894

Lopez-Feldman A, Heres D, Marquez-Padilla F. 2021. Air pollution exposure and Covid-19: a look at mortality in Mexico city using individual-level data. Sci Total Environ 756:143929.

Rheinlander A, Schraven B, Bommhardt U (2018) Cd45 in human physiology and clinical medicine. Immunol Lett 196:22-32

Rivas-Santiago CE, Sarkar S, Pt C, Osornio-Vargas A, Quintana-Belmares R, Meng Q et al (2015) Air pollution particulate matter alters antimycobacterial respiratory epithelium innate immunity. Infect Immun 83:2507-2517

Sack C, Vedal S, Sheppard L, Raghu G, Barr RG, Podolanczuk A, et al. 2017. Air pollution and subclinical interstitial lung disease: the multi-ethnic study of atherosclerosis (mesa) air-lung study. Eur Respir J 50.

Sandstrom T, Helleday R, Bjermer L, Stjernberg N (1992) Effects of repeated exposure to $4 \mathrm{ppm}$ nitrogen dioxide on bronchoalveolar lymphocyte subsets and macrophages in healthy men. Eur Respir J 5:1092-1096

Solomon C, Christian DL, Chen LL, Welch BS, Kleinman MT, Dunham E et al (2000) Effect of serial-day exposure to nitrogen 
dioxide on airway and blood leukocytes and lymphocyte subsets. Eur Respir J 15:922-928

Song JW, Zhang C, Fan X, Meng FP, Xu Z, Xia P et al (2020) Immunological and inflammatory profiles in mild and severe cases of Covid-19. Nat Commun 11:3410

Steenhof M, Janssen NA, Strak M, Hoek G, Gosens I, Mudway IS et al (2014) Air pollution exposure affects circulating white blood cell counts in healthy subjects: the role of particle composition, oxidative potential and gaseous pollutants-the raptes project. Inhalation Toxicol 26:141-165

Stufano A, Lisco S, Bartolomeo N, Marsico A, Lucchese G, Jahantigh $\mathrm{H}$, et al. 2021. Covid 19 outbreak in Lombardy, Italy: an analysis on the short-term relationship between air pollution, climatic factors and the susceptibility to Sars-Cov-2 infection. Environ Res 198:111197.

Valiathan R, Ashman M, Asthana D (2016) Effects of ageing on the immune system: infants to elderly. Scand J Immunol 83:255-266

Villeneuve PJ, Goldberg MS (2020) Methodological considerations for epidemiological studies of air pollution and the Sars and Covid-19 coronavirus outbreaks. Environ Health Perspect 128:95001

Wang D, Hu B, Hu C, Zhu F, Liu X, Zhang J et al (2020) Clinical characteristics of 138 hospitalized patients with 2019 novel coronavirus-infected pneumonia in Wuhan, China. JAMA 323:1061-1069

Williams L, Ulrich CM, Larson T, Wener MH, Wood B, Chen-Levy Z et al (2011) Fine particulate matter (pm(2). (5)) air pollution and immune status among women in the seattle area. Arch Environ Occup Health 66:155-165

Woodby B, Arnold MM, Valacchi G (2021) Sars-Cov-2 infection, Covid-19 pathogenesis, and exposure to air pollution: what is the connection? Ann N Y Acad Sci 1486:15-38

World Health Organization. 2021. Who Covid-19 dashboard Available: https://covid19.who.int [accessed 18/12/2021].

Wu C, Chen X, Cai Y, Xia J, Zhou X, Xu S et al (2020) Risk factors associated with acute respiratory distress syndrome and death in patients with coronavirus disease 2019 pneumonia in Wuhan, China. JAMA Intern Med 180:934-943

Xu Z, Shi L, Wang Y, Zhang J, Huang L, Zhang C et al (2020) Pathological findings of Covid-19 associated with acute respiratory distress syndrome. Lancet Respir Med 8:420-422

Yan W, Chen D, Bigambo FM, Wei H, Wang X, Xia Y (2021) Differences of blood cells, lymphocyte subsets and cytokines in Covid19 patients with different clinical stages: a network meta-analysis. BMC Infect Dis 21:156

Zhang G, Zhang J, Wang B, Zhu X, Wang Q, Qiu S (2020) Analysis of clinical characteristics and laboratory findings of 95 cases of 2019 novel coronavirus pneumonia in Wuhan, China: a retrospective analysis. Respir Res 21:74

Publisher's note Springer Nature remains neutral with regard to jurisdictional claims in published maps and institutional affiliations. 